\title{
Phenolic compounds and biological activities of phenolic extract of olive oil mill wastewater issue from the cold extraction of olive oil from Khenchela (Algeria)
}

\section{Zakia Gueboudji}

Universite Abbes Laghrour Khenchela

Kenza Kadi ( $\sim$ kadikenza79@gmail.com)

Universite Abbes Laghrour Khenchela https://orcid.org/0000-0003-2866-635X

Kamel Nagaz

IRA Tunisia

Dalila Addad

Universite Abbes Laghrour Khenchela

Mansour Secrafi

IRA Mednine Tunisia

Leila Ben Yahya

IRA mednine Tunisia

Belgacem Lachehib

IRA mednine Tunisia

\section{Research Article}

Keywords: OMW, antioxidant activity, anti-inflammatory activity, anticoagulant activity, cold extraction, LCMS, phenolic compounds.

Posted Date: April 12th, 2021

DOl: https://doi.org/10.21203/rs.3.rs-360101/v1

License: (9) This work is licensed under a Creative Commons Attribution 4.0 International License. Read Full License 


\section{Abstract}

This study aimed to the determination of antioxidant, anti-inflammatory, and anticoagulant activities of phenolic compounds present in olive oil mill wastewater (OMW) issue from the cold extraction of olive oil from Khenchela eastern of Algeria.After polyphenols extraction, a quantity and quality analysis by LC-MS was made. The LC-MS (liquid chromatography-mass spectrometry)results were revealed the presence of 20 phenolic compounds in theextract of OMW which were: (quinic acid, gallic acid, protocatechuic acid, caffeic acid, p-coumaric acid, rutin, transfrolic acid, hyperoside (quercetin-3-o-galactoside), luteolin-7-oglucoside, naringin, 4.5-di-caffeoyquinic acid, quercetrin (quercetin-3-o-rhamonosid), apegenin-7-oglucoside, salviolinic acid, kampherol, quercetin, naringenin, apegenin,cirsiliol, and cirsilineol). The results of antioxidant activity with DPPH(2,2-diphenyl-1-picrylhydrazyl), ABTS+ (2,2'-azino-bis (3ethylbenzothiazoline-6-sulfonic acid), and FRAP (ferric reducing ability of plasma)showed that the $\mathrm{IC}_{50}$ (half-maximal inhibitory concentration) were $(9.62 \pm 0.28 \mu \mathrm{g} / \mathrm{mL}, 7.10 \pm 0.11 \mu \mathrm{g} / \mathrm{mL}$ and $3.59 \pm$ $0.24 \mu \mathrm{g} / \mathrm{mL}$ ) respectively. The extract of OMW was found to exhibit the highestinhibitory effectantiinflammatory activity usinginhibition of protein denaturation(IPD) and membrane stabilizing potential (MSP) tests $(80.46 \pm 3.81 ; 87.43 \pm 0.66 \mu \mathrm{g} / \mathrm{mL})$ more than the standard used. In addition, the extract had the best anticoagulation activity in the endogenous and exogenous pathways $(44.77 \pm 0.25 \mathrm{~s} ; 15.84 \pm$ $0.12 \mathrm{~s}$ ). Based on these results, it is right to conclude that $\mathrm{OMW}$ is an important source of natural phenolic compounds that have important antioxidant, anti-inflammatory, and anticoagulant activities.

\section{Introduction}

By-products of olive oil production represent a major disposal problem for the food industry, but they are also promising sources of bioactive compounds. Olive oil mill wastewater (OMW), one of the mains byproducts of olive oil production (Cedola et al., 2020). In fact, after oil extraction, OMW contained $98 \%$ of the total phenolic content of the olive fruits with concentrations varying from 0.5 to $24 \mathrm{~g} / \mathrm{L}$ (Alaoui et al., 2016), such as hydroxytyrosol, tyrosol, and flavonoids (Tzathas et al., 2019). Pollution mainly due to the high concentrations of phenolic compounds (Babićet al., 2019).OMW is an aqueous, dark, foul-smelling, and turbid liquid, which includes emulsified grease; it is easily fermentable (Goula and Gerasopoulos, 2017). It characterized by an acidic pH (between 3.0 and 5.9), high conductivity, a solid content ranging from 4.1 to $16.4 \%$. It may contain up to $150 \mathrm{~g} / \mathrm{L}$ to total solids (TS), water (between $83 \%$ and $92 \%$ ), high chemical oxygen demand COD (between 40 and $220 \mathrm{~g} / \mathrm{L}$ ), also biochemical oxygen demand BOD 5 (between 35 and $170 \mathrm{~g} / \mathrm{L}$ ) (Dermache et al., 2013). All these results in a toxic effect onsoil, microorganisms, plants, and marine organisms (Morón et al., 2018; Basic et al., 2019). Moreover, the main components of OMW are phenolic compounds, sugars, and organic acids, mineral nutrients especially potassium (Dermache et al., 2013). The difference in its compositions is due to different factors such as olive variety, the method of extraction, the technological process separation, the climatic conditions, olive storage time, and the fruit maturity of the olive tree (Dermache et al., 2013; Aggoun et al., 2016). Phenolic compounds have manybiological properties, in particular the antioxidant, anti- 
inflammatory, and anticoagulant activities, which used in the pharmaceutical industry (Khana et al., 2020).

Oxidative stress is unsteady in the balance between the defense system of antioxidants and the production of reactive oxygen species (ERO) (Power et al., 2010). This leads to biochemical damage in the cells of the organism due to their molecular consequences, such as alterations in proteins, the appearance of breaks in DNA, or damage to the integrity of the cell membrane by the induction of lipid peroxidation (Shilpa et al., 2017).Oxidative stress has actually been described as a crucial etiological factor involved in various chronic human diseases such as cancer, cardiovascular and neurodegenerative diseases, inflammation, diabetes mellitus, and aging (Uttara et al., 2009).Inflammation and coagulation are two main host-defense systems that interact with each other (Petäjä, 2011). They are implicated in many cardiovascular diseases such as thrombosis and atherosclerosis (Strukova, 2006).Inflammation is a physicochemical process in response to tissue damage resulting from microbial pathogen infection, chemical irritation, and/or wounding (Serhan et al., 2008). Thromboembolic diseases continue to be the leading cause of death throughout the world (Wu et al., 2015). As is well-known, thrombosis is closely related to activating platelet adhesion, aggregation, secretion functions, and activation of intrinsic and extrinsic coagulation systems, which cause blood coagulation and fibrin formation (Xin et al., 2011). Therefore, anticoagulants play a pivotal role in the prevention and treatment of thrombotic disorders (Xu et al., 2016).Diseases arising from blood clotting, including pulmonary emboli, deep vein thrombosis, and cardiovascular diseases are the major causes of death and disability worldwide (Who, 2017).

The main objective of this study is to evaluate the antioxidant, anti-inflammatory, and anticoagulant activities of phenolic compounds present in OMW issue from the cold extraction of olive oil from Khenchela eastern Algeria.

\section{Material And Methods}

\subsection{Physicochemical properties}

The olive oil mill wastewater (OMW) was obtained from a modern olive mill situated in Khenchela, eastern Algeria in November 2019.It was collected directly from the decanter, frozen immediately and kept at ${ }^{-} 20^{\circ} \mathrm{C}$ until use.

Different physicochemical parameters including $\mathrm{pH}$, electrical conductivity (EC), dry matter (DM), organic matter (OM), mineral matter (MM), biological oxygen demand (BOD), and chemical oxygen demand (COD) were performed according to the Standard Methods (APHA, 2005). The $\mathrm{pH}$ value was determined with a pH meter (AdwaAD1000). Electrical Conductivity (EC) was determined by a conductivity meter type (inoLab WTW). Dry matter content (DM) was measured by drying at $105^{\circ} \mathrm{C}$ for $24 \mathrm{~h}$. Organic matter (OM) was calculated by the differencebetween the dry weight of the OMW and its weight after the calcination. Mineral matter (MM) was determined by weighing after ignition in a muffle furnace type (Nabertherm) at $550^{\circ} \mathrm{C}$, for 24 hours. The chemical oxygen demand (COD) was determined using potassium dichromate, 
as described by $\mathrm{BOD}_{5}$ (biological oxygen demand) is determined by the respirometric method. Analyzes were carried out in triplicate.

\subsection{Polyphenol extraction methods}

The extraction of phenolic compounds was done according to the maceration method. $1 \mathrm{~g}$ of OMW powder was mixed with $10 \mathrm{~mL}$ of pure methanol, the mixture was vortexed for $15 \mathrm{~min}$, and then let macerate in the dark overnight at $4^{\circ} \mathrm{C}$. After maceration, filtration using filter paper is carried out. The macerate was collected and was added to $10 \mathrm{~mL}$ of methanol $(90 \%)$ for a second time, the mixture is vortexed for $15 \mathrm{~min}$ and leaves to macerate for 1 hour. The two filtrates are combined and filtered through cellulose paper containing sodium sulfate. Then this solution was concentrated at $40^{\circ} \mathrm{C}$ in a rotary evaporator type (HAHNVAPOR) and the dry residue is stored.

\subsection{Total phenolic content (TPC)}

The total phenolic content was determined following the Folin-Ciocalteu method (Makkar et al., 1993) and the results were expressed as milligrams of gallic acid equivalents per milliliter of extract ( $\mathrm{mg}$ $\mathrm{GAE} / \mathrm{mL}$ ). The total phenolic content (TPC) of extracts was estimated according to the calibration curve prepared from gallic acid $\left(y=0.0046 x+0.0108, R^{2}=0.9967\right)$.

\subsection{Total flavonoids content (TFC)}

The quantification of total flavonoids content was performed by (Ayoola et al., 2008) method and the results were expressedas milligrams rutin equivalents per milliliter of extract ( $\mathrm{mg} \mathrm{RE} / \mathrm{mL}$ ). The total flavonoids content (TFC) was calculated following the calibration curve prepared from rutin $(y=0.0103 x$ $\left.+0.0061, R^{2}=0.9963\right)$.

\subsection{Tannin condensed content (TCC)}

The quantification of condensed contentwas performed according to the method of (Dewanto et al., 2002) by reaction with vanillin in the presence of sulfuric acid. It is expressedin milligrams of catechuic acid equivalent permilliliter of extract $(\mathrm{mg} \mathrm{CAE} / \mathrm{mL})$. The tannins condensed content (TCC) was estimated according to the calibration curve prepared from catechuic acid $\left(y=0.0066 x+0.0113, R^{2}=\right.$ 0.9969).

\subsection{LC-MS separation and identification of phenolic compounds}

The analysis for phenolic compounds was performed on a Shimadzu UFLC XR system (Kyoto, Japan), equipped with a SIL-20AXR auto-sampler, a CTO-20 AC column oven, a LC-20ADXR binary pump and a quadripole 2020 detector system. This instrument was equipped with an Inertsil ODS-4 C18 $3 \mu \mathrm{m}$ column $\left(\mathrm{L} 150 \times 3.0 \mathrm{~mm}\right.$ i. d). The column temperature was set at $40^{\circ} \mathrm{C}$ and the injection volume was $20 \mu \mathrm{l}$ with a flow rate of $0.5 \mathrm{ml} / \mathrm{min}$. eau $95 \%+\mathrm{MeOh} 5 \%+0.2 \%$ Acetic acid and $50 \% \mathrm{ACN}+50 \% \mathrm{H} 2 \mathrm{O}+0.2 \%$ Acetic acid were used as mobile phases $A$ and $B$, respectively. The analysis was performed using a linear gradient programmed as follows: $0,01-14 \mathrm{~min}$, from $10-20 \% \mathrm{~B} ; 14-27 \mathrm{~min}, 0$ from $20-55 \% \mathrm{~B} ; 27-37 \mathrm{~min}$, from $55-100 \%$ B ; $37-45 \mathrm{~min}, 100 \%$ B ; $45-50$ min $10 \%$ B. Dissolving line temperature was $275^{\circ} \mathrm{C}$, nebulizing gas flow $1,50 \mathrm{~L} / \mathrm{min}$, the drying gas was set at $15,00 \mathrm{~L} / \mathrm{min}$ and Temperature of Heat block was $450^{\circ} \mathrm{C}$. LC- 
ESI (-) MS mass spectra [M-H] - were acquired using Lab Solutions software. Phenolic compoundswere identified by comparison with retention time of the standards of phenolic compounds. The lab standards were LGC and Sigma Aldrich.

\subsection{Antioxidant assays}

\subsubsection{DPPH free radical-scavenging activity}

The antioxidant activity of different extractions was evaluated following Ozgen et al. (2006)method using the free radical DPPH(2,2-diphenyl-1-picrylhydrazyl). The results were given as $50 \%$ inhibition concentration $\left(\mathrm{IC}_{50}\right)$ and compared with the antioxidant standards (BHT, Ascorbic acid and Trolox).

\subsubsection{ABTS $^{+}$free radical scavenging activity}

The ABTS (2,2-Azino-bis-3-ethylbenzothiazoline-6-sulfonic acid) scavenging activity was determined according to the method of (Ozgen et al., 2006). The results were given as $50 \%$ inhibition concentration $\left(\mathrm{IC}_{50}\right)$ and compared with the antioxidant standards (BHT, Ascorbic acid, and Trolox).

\subsubsection{FRAP ferric reducing antioxidant power}

The FRAP activity was evaluated following (Ozgen et al., 2006). The results were given as $50 \%$ inhibition concentration $\left(\mathrm{IC}_{50}\right)$ and compared with the antioxidant standards (BHT, Ascorbic acid, and Trolox).

\subsection{Anti-inflammatory activity}

\subsubsection{Inhibition of protein denaturation(IPD)}

It is determined by the method described by Kandikattu, (2013)with slight modifications.

The principle consists of the inhibition of denaturation of BSA caused by heat $\left(72^{\circ} \mathrm{C}\right)$ by the phenolic extract of OMW. $1 \mathrm{~mL}$ of each concentration of extract added to $1 \mathrm{~mL}$ of $0.2 \%$ BSA solution prepared in Tris- $\mathrm{HCl} \mathrm{pH} \mathrm{6.6,} \mathrm{then} \mathrm{incubated} \mathrm{at} 37^{\circ} \mathrm{C}$ for $15 \mathrm{~min}$ then in a water bath at $72^{\circ} \mathrm{C}$ for $5 \mathrm{~min}$. After cooling, the turbidity is measured at $600 \mathrm{~nm}$ in a cell spectrophotometer (SPECORD210plus). The same protocol for diclofenac sodium standard (injectable form) which was prepared at different concentrations in ultrapure distilled water from a 500ppm mother solution and distilled water was used as a negative control.

\subsubsection{Membrane stabilizing potential (MSP)}

It was measured according to Murugan and Parimelazhagan (2014). An equal volume of blood drawn from a healthy human volunteer who had not taken NSAIDs for two weeks before blood collection, and was mixed with an equal volume of sterilized Alsever solution. This blood solution was centrifuged at $3000 \mathrm{rpm}$ for $10 \mathrm{~min}$, the packed cells were separated and then washed with iso-saline solution, and a $10 \%(\mathrm{v} / \mathrm{v})$ suspension was prepared with iso-saline. The dosage mixture contains $1 \mathrm{~mL}$ of phosphatebuffered saline, $0.5 \mathrm{~mL}$ of $10 \%$ blood suspension, $0.5 \mathrm{~mL}$ of phenolic extract of OMW with different concentrations and $2 \mathrm{ml}$ of hypotonic saline. All test mixtures were incubated at $37^{\circ} \mathrm{C}$ for $30 \mathrm{~min}$ and then centrifuged at $3000 \mathrm{rpm}$ for $20 \mathrm{~min}$. The supernatant was separated and the hemoglobin content was estimated by spectrophotometric reading at $560 \mathrm{~nm}$. The negative control was distilled water and the 
positive control was diclofenac sodium at the final concentration.Again, the $\mathrm{IC}_{50}$ was calculated from a graph defining inhibition against the different concentrations.

\subsection{Anticoagulant activity in vitro}

\subsubsection{Endogenous coagulation pathway (APTT)}

Activating partial thromboplastin time (APTT) was determined according to Wang et al. (2010).A pool of platelet plasma consisting of a plasma mixture of 10 healthy untreated volunteers whose APTT and PT were normal. The activity of the phenolic extract was established on a volume of $100 \mu \mathrm{L}$ whose plasma is $90 \mu \mathrm{l}$ was mixed with $10 \mu \mathrm{L}$ of extract. After $15 \mathrm{~min}$ of incubation at $37^{\circ} \mathrm{C} 100 \mu \mathrm{Lcephalin}$ kaolin was added to the mixture, which was re-incubated for $3 \mathrm{~min}$ with agitation at $37^{\circ} \mathrm{C}$. The coagulation time was determined using a coagulometer by adding $100 \mu \mathrm{L}$ of preheated calcium chloride $(0.025 \mathrm{M})$.In parallel, positive control of calciparine (unfractionated heparin) and a negative control test (substitution of the samples with a $0.9 \% \mathrm{NaCl}$ solution was carried out under the same conditions.An elongation of APTT in the presence of the polyphenols relative to the negative control indicates an anticoagulant effect at the level of this pathway. Clotting time was determined by an automatic coagulation analysis system (CoaDATA 4004).

\subsubsection{Exogenous coagulation pathway (PT)}

Prothrombin time (PT)was determined according to the protocol described by Wang et al.(2010).This activity consists of measuring the coagulation time of citrated plasma in the presence of an excess of calcium thromboplastin. Using platelet-poor plasma in the presence of calcium thromboplastin.100 $\mu \mathrm{L}$ of platelet-poor plasma preheated for $2 \mathrm{~min}$ at $37^{\circ} \mathrm{C}$ was mixed with the phenol extract ( 90 and $10 \mu \mathrm{L}$ by order). After $15 \mathrm{~min}$ of incubation at $37^{\circ} \mathrm{C}, 200 \mu \mathrm{L}$ of calcium thromboplastin preheated at least $15 \mathrm{~min}$ at $37^{\circ} \mathrm{C}$ was added to the mixture. Coagulation time was determined by an automatic coagulation analysis system(CoaDATA 4004).

\subsection{Statistical study}

Data obtained were presented as (mean \pm standard) deviation of three dependent determinations. Significant differences between means of total phenolic, total flavonoids, tannins and LC-MS analysis results were determined by Student t-test, and $p$ values $(<0.05)$ were regarded as significant. Results of antioxidant, anti-inflammatory and anticoagulant activities were subjected to statistical analysis of variance (ANOVA) using ECXEL STAT (version 2014) package at $p<0.05$ significant levels.

\section{Results And Discussion}

\subsection{Physicochemical properties}


Table 1

Physicochemical properties of OMW studied

\begin{tabular}{|c|c|c|c|c|c|c|}
\hline $\mathrm{pH}$ & $\mathrm{EC}(\mathrm{mS} / \mathrm{cm})$ & TSS\% & $\mathrm{DM}(\mathrm{g} / \mathrm{L})$ & $\mathrm{OM}(\mathrm{g} / \mathrm{L})$ & $\mathrm{BOD}_{5}(\mathrm{~g} / \mathrm{L})$ & $\operatorname{COD}(g / L)$ \\
\hline $\begin{array}{l}4.9 \\
\pm \\
0.01\end{array}$ & $12.89 \pm 0.09$ & $0.9 \pm 0.03$ & $110.8 \pm 3.17$ & $53.7 \pm 1.16$ & $68 \pm 2.28$ & $170 \pm 8.5$ \\
\hline $\begin{array}{l}\text { The p } \\
\text { result } \\
\text { matte } \\
=68 \pm \\
\text { (TSS9 }\end{array}$ & $\begin{array}{l}\text { sicochemical } \\
\text { OMW was an } \\
\text { expressed in } t \epsilon \\
.28 \mathrm{~g} / \mathrm{L} \text { ) and } \mathrm{i} \\
0.9 \pm 0.03) \text {. }\end{array}$ & $\begin{array}{l}\text { ies of OMW } \\
\text { quid effluen } \\
\text { a high value } \\
=170 \pm 8.5 \mathrm{~g}\end{array}$ & $\begin{array}{l}\text { udied were pre } \\
(\mathrm{pH}=4.9 \pm 0.0 \\
\mathrm{f} \text { electrical cor } \\
-),(\mathrm{DM}=110.8\end{array}$ & , too loade & $\begin{array}{l}\text { 1. Based on } t \\
\text { ith mineral a } \\
2.89 \pm 0.09 \mathrm{~m} \\
1=537+11\end{array}$ & $\begin{array}{l}\text { btained } \\
\text { organic } \\
\mathrm{cm}),\left(\mathrm{BOD}_{5}\right. \\
/ \mathrm{L}) \text {, and }\end{array}$ \\
\hline
\end{tabular}

OMW's composition is widely discussed in the literature, and our results are similar to several founded results. OMW is an acidic liquid, with $\mathrm{pH}$ values from 3 to 5 , and with an electrical conductivity value of $16.79 \mathrm{mS} / \mathrm{cm}$. Generally, it composed of dry matter (6-17\%), organic matter (4 to $16 \%)$, chemical oxygen demand (COD) $(40-220 \mathrm{~g} / \mathrm{L})$ BOD $_{5}(35-110 \mathrm{~g} / \mathrm{L})$ and the presence of several phenol-type molecules (0.5- $24 \mathrm{~g} / \mathrm{L})$ (El Moudden et al., 2020; Kadi et al., 2020). The quality and quantity of OMW are both very different and are influenced by different factors, such as type of production process, olives, use of pesticides and fertilizers, the area cultivated, weather conditions and stage of ripening olives(El-Abbassi et al., 2017).

\subsection{Total phenolic, flavonoids and tannins content}

The results of total phenolic, flavonoids and tannin condensed contentswere summarized in Table 2. The results of the test $t$ of Student showed that there is a significant difference between means of total polyphenols, total flavonoids and condensed tannins.

Table 2

Total polyphenols, flavonoids and condensed tannins of phenolic extract of OMW

\begin{tabular}{|llll|}
\hline Secondary metabolites & $\begin{array}{l}\text { Total polyphenols } \\
(\mathrm{mg} \mathrm{GAE} / \mathrm{mL})\end{array}$ & $\begin{array}{l}\text { Total flavonoids } \\
(\mathrm{mg} \mathrm{RE} / \mathrm{mL})\end{array}$ & $\begin{array}{l}\text { Condensed tannins } \\
(\mathrm{mg} \mathrm{CAE} / \mathrm{mL})\end{array}$ \\
\hline Concentration & $10.82 \pm 0.11$ & $3.11 \pm 0.16$ & $2.43 \pm 0.15$ \\
\hline
\end{tabular}

Our results showed that OMW is characterized by the richness of phenolic compounds. The phenolic composition obtained from the extract of OMW was total polyphenols $(10.82 \pm 0.11 \mathrm{mg} \mathrm{GAE} / \mathrm{mL})$, total flavonoids $(3.11 \pm 0,16 \mathrm{mg} \mathrm{RE} / \mathrm{mL}$ ) and condensed tannins $(2.43 \pm 0.15 \mathrm{mg} \mathrm{TAE} / \mathrm{mL})$. The results that we obtained were higher than of those obtained by Kadi et al. (2020).

\subsection{Identification and quantification of phenolic compounds by LC-MS analysis}


The quantitative analysis results of major phenolic compounds identified in the extract of OMW were summarized in Table 3. 
Table 3

LC-MS analysis of phenolic extract of OMW

\begin{tabular}{|c|c|c|c|c|}
\hline $\mathrm{N}^{0}$ & Phenolic acids & Retention time & $M / h$ & Concentration ppm \\
\hline 1 & Quinic acid & 2.030 & 191 & $194.53 \pm 29.092$ \\
\hline 2 & Gallic acid & 4.109 & 169 & $65.925 \pm 91.78$ \\
\hline 3 & Protocatechuic acid & 7.409 & 153 & $195.356 \pm 58.578$ \\
\hline 4 & Catechin (+) & - & 289 & N.D.(Peak) \\
\hline 5 & Caffeic acid & 15.983 & 179 & $29.262 \pm 9.519$ \\
\hline 6 & Syringic acid & - & 197 & N.D.(Peak) \\
\hline 7 & 1,3-di-O-caffeoyquinic acid & - & 515 & N.D.(Peak) \\
\hline 8 & Epicatechin & - & 289 & N.D.(Peak) \\
\hline 9 & p-coumaric acid & 22.117 & 163 & $21.935 \pm 5.604$ \\
\hline 10 & Rutin & 24.931 & 609 & $2.106 \pm 0.445$ \\
\hline 11 & Transfrolic acid & 24.280 & 193 & $2.708 \pm 4.69$ \\
\hline 12 & Hyperoside (quercetin-3-o-galactoside & 25.072 & 463 & $4.801 \pm 0.655$ \\
\hline 13 & Luteolin-7-o-glucoside & 25.676 & 447 & $15.445 \pm 1.365$ \\
\hline 14 & 3,4-di-O-caffeoyquinic acid & - & 515 & N.D.(Peak) \\
\hline 15 & Naringin & 27.040 & 579 & $16.721 \pm 0.532$ \\
\hline 16 & Rosmarinic acid & - & 359 & N.D.(Peak) \\
\hline 17 & 4,5-di-O-caffeoyquinic acid & 27.648 & 515 & $676.57 \pm 83.712$ \\
\hline 18 & Quercetrin (quercetin-3-o-rhamonosid & 27.924 & 447 & $12.310 \pm 1.248$ \\
\hline 19 & Apegenin-7-o-glucoside & 27.906 & 431 & $0.732 \pm 1.269$ \\
\hline 20 & o-coumaric acid & - & 163 & N.D.(Peak) \\
\hline 21 & Salviolinic acid & 28.918 & 717 & $33.82 \pm 2.943$ \\
\hline 22 & Kampherol & 32.879 & 285 & $906.831 \pm 306.164$ \\
\hline 23 & Quercetin & 32.876 & 301 & $2.457 \pm 0.291$ \\
\hline 24 & Trans cinnamic & - & 147 & N.D.(Peak) \\
\hline 25 & Naringenin & 34.783 & 271 & $1.367 \pm 2.368$ \\
\hline 26 & Apegenin & 35.421 & 269 & $96.2 \pm 10.05$ \\
\hline
\end{tabular}




\begin{tabular}{|c|c|c|c|c|}
\hline N $^{\circ}$ & Phenolic acids & Retention time & $M / h$ & Concentration ppm \\
\hline 27 & Luteolin & - & 285 & N.D.(Peak) \\
\hline 28 & Cirsiliol & 36.468 & 329 & $51.258 \pm 2.664$ \\
\hline 29 & Cirsilineol & 39.017 & 343 & $2.924 \pm 5.065$ \\
\hline 30 & Acacetin & - & 283 & N.D.(Peak) \\
\hline \multirow[t]{2}{*}{31} & Chlorogenic acid & 353 & & N.D.(Peak) \\
\hline & Total phenols & - & & $2333.258 \pm 220.565$ \\
\hline
\end{tabular}

Thirty-one (31) compounds were screened by liquid chromatography-mass spectrometry LC-MS. Only twenty (20) compounds were identified and quantified in the extract. They were quinic acid, gallic acid, protocatechuic acid, caffeic acid, p-coumaric acid, rutin, transfrolic acid, hyperoside (quercetin-3-ogalactoside), luteolin-7-o-glucoside, naringin, 4.5-di-caffeoyquinic acid, quercetrin (quercetin-3-orhamonosid), apegenin-7-o-glucoside, salviolinic acid, kampherol, quercetin, naringenin, apegenin, cirsiliol, and cirsilineol. The major identified phenolic compounds were kampherol, 4.5-di-o-caffeoyquinic acid, protocatechuic acid, and quinic acid with the concentrations $(906.831 \pm 306.164,676.57 \pm 83.712$, $195.356 \pm 58.578$ and $194.53 \pm 29.092$ ppm). Their structures were presented in Fig. 1

Several researchers were identified phenolic compounds by HPLC as; Ben Saad et al. (2020) that were identified sixteen peaksby HPLC-DAD-ESI/MS.There wereHydroxytyrosol, Para-hydroxyphenyl acetic acid derivative, Pinoresinol, Apigenin 7-0-glucoside, Luteolin-7-rutinoside, Naringenin, Luteolin-7glucoside, Syringic acid, 7- $\beta$-1-d-Glucopyranosyl-11-methyl oleoside, Elenolic acid, Hydroxy-0decarboxymethyl oleuropeinaglycon, Luteolin, Apigenin, Diosmetin, and Hydroxytyrosol glycoside.

\section{Antioxidant activities by DPPH. ${ }^{+}$, ABTS $^{+}$and FRAP assays}

The antioxidant activity of phenolic extract of OMW was shown in Table 4. The free radical scavenging activity determined by DPPH., ABTS. ${ }^{+}$and FRAP is widely used to estimate antiradical/ antioxidant capacity of phenolic compounds of OMW and compared the results with several reference standards with the aim to achieve more informative and arguably necessary results. 
Table 4

Antioxidants activity of phenolic extract of OMW by DPPH, ABTS, and FRAP

\begin{tabular}{|llll|}
\hline & DPPH IC50 $\mu \mathrm{g} / \mathrm{mL}$ & ABTS IC50 $\mu \mathrm{g} / \mathrm{mL}$ & FRAP IC50 $\mu \mathrm{g} / \mathrm{mL}$ \\
\hline Extract & $9.62 \pm 0.28$ & $7.10 \pm 0.11$ & $3.59 \pm 0.24$ \\
\hline BHT & $20.03 \pm 0.25$ & $4.27 \pm 0.38$ & $18.81 \pm 0.09$ \\
Ascorbic Acid & $20.84 \pm 0.65$ & $2.03 \pm 0.14$ & $11.08 \pm 0.18$ \\
\hline Rutin & $10.5 \pm 0.36$ & $8.48 \pm 0.33$ & $4.72 \pm 0.21$ \\
\hline
\end{tabular}

The results of DPPH scavenging showed that the phenolic extract of OMWhas exhibited the highest antioxidant activity $\left(\mathrm{IC}_{50}: 9.62 \pm 0.28 \mu \mathrm{g} / \mathrm{mL}\right)$ closer activity to that of rutin $\left(\mathrm{IC}_{50}: 10.5 \pm 0.36 \mu \mathrm{g} / \mathrm{mL}\right)$ and more than BHT and ascorbic acid which are in the same group which $\mathrm{IC}_{50}$ are $(20.03 \pm 0.25$ and $20.84 \pm$ $0.65 \mu \mathrm{g} / \mathrm{mL}$ ), respectively. Similarly, the analysis data of the ABTS assay showed that the phenolic extract of $\mathrm{OMW}$ had an $\mathrm{IC}_{50}$ higher than rutin $\left(\mathrm{IC}_{50}: 7.10 \pm 0.11,8.48 \pm 0.33 \mu \mathrm{g} / \mathrm{mL}\right)$ and lower than ascorbic acid and BHT ( $\left(\mathrm{C}_{50}: 2.03 \pm 0.14,4.27 \pm 0.38 \mu \mathrm{g} / \mathrm{mL}\right)$. From the results of FRAP, phenolic extract of OMW was exhibiting the best antioxidant activity $\left(\mathrm{IC}_{50}: 3.59 \pm 0.24 \mu \mathrm{g} / \mathrm{mL}\right)$ than rutin $\left(\mathrm{IC}_{50}: 4.72 \pm 0.21\right.$ $\mu \mathrm{g} / \mathrm{mL})$, ascorbic acid $\left(\mathrm{IC}_{50}: 11.08 \pm 0.18 \mu \mathrm{g} / \mathrm{mL}\right)$ and $\mathrm{BHT}\left(\mathrm{IC}_{50}: 18.81 \pm 0.09 \mu \mathrm{g} / \mathrm{mL}\right)$.

El Moudden et al. (2020) showed that the phenolic compounds of OMWare characterized by a strong antioxidant activity. In literature, the in vitro antioxidant activity of natural extracts has been widely discussed. These methods involve the presence of oxidizing species such as free radicals or metal complexes oxidized in the presence of an extract, which contains antioxidants capable of inhibiting the generation of radicals. Several studies have shown that the antioxidant activity depends on the concentration of total polyphenols, on the nature and structure of the antioxidants in the extract. In addition, the concentration of total polyphenols was significantly correlated with the antioxidant capacity evaluated by the DPPH and ABTS tests.

According to Stoclet and Schini-Kerth (2011), at the cellular level, certain flavonoids can act on the transmission of signals by protein kinases, including the expression of antioxidant and anti-inflammatory genes and vice-versa, the inhibition of oxidative and inflammatory genes.

The load of the total phenolic content and the type of phenolic compounds can explain the strong antioxidant activity of our extracts. In addition, perhaps this strong antioxidant activity due to the flavonoid contents, especially kampherol(Calderón-Montaño et al., 2011), which is the most abundant flavonoid in our extract $(906.831 \pm 306.164 \mathrm{ppm})$.

\subsection{Anti-inflammatory activity}

\subsubsection{Inhibition of protein denaturation(IPD)}


The results of the denaturing effect of proteins were illustrated in Table 5. The studied phenolic extract of OMW has an inhibitory efficiency of thermal denaturation $\left(\mathrm{IC}_{50}=80.46 \pm 3.81 \mu \mathrm{g} / \mathrm{mL}\right)$ superior to that of the reference anti-inflammatory drug diclofenac sodium $\left(\mathrm{IC}_{50}=83.83 \pm 0.21 \mu \mathrm{g} / \mathrm{mL}\right)$.

Table 5

Anti-inflammatory activity of phenolic extract of OMW

\begin{tabular}{|lll|}
\hline & IPD IC50 $\mu \mathrm{g} / \mathrm{mL}$ & MSP IC50 $\mu \mathrm{g} / \mathrm{mL}$ \\
\hline Extract & $80.46 \pm 3.81$ & $87.43 \pm 0.66$ \\
\hline Diclofenac sodium & $83.83 \pm 0.21$ & $95.31 \pm 0.69$ \\
\hline
\end{tabular}

By their stabilizing effect on proteins, the extract, therefore, has an anti-inflammatory potential, which remains to be confirmed by other in vivo tests.

Indeed, the conformation of a protein is linked to the secondary and tertiary structure; it is carried out by means of lower energy bonds (hydrogen bonds, electrostatic, hydrophobic and disulfide bridges), therefore fragile. Denaturation results from a modification of the quaternary, tertiary and secondary structures without fragmentation of the peptide chain under the effect of various chemical or physical agents (Karthik et al., 2013; Marliyahand Ananthi, 2015). The denaturation of a protein causes the induction of the inflammatory reaction by the production of auto-antigens, important factors for developing chronic inflammation (Karthik et al., 2013).

Recent studies have shown that many flavonoids and related polyphenols have significantly contributed to antioxidant and anti-inflammatory activities (Govindappa et al., 2011).

The presence of these bioactive compounds in the OMW extract can contribute to this anti-inflammatory activity.

Therefore, the use of agents that can prevent protein denaturation would be useful for the development of anti-inflammatory drugs (Chatterjee et al., 2012).

\subsubsection{Membrane stabilizing potential (MSP)}

The results of the membrane-stabilizing effect of the OMW phenolic extract were illustrated in Table 5.According to the results obtained, the extract had a high inhibitory concentration $\left(\mathrm{IC}_{50}=87.43 \pm 0.66\right.$ $\mu \mathrm{g} / \mathrm{mL})$ compared to diclofenac sodium $\left(\mathrm{IC}_{50}=95.31 \pm 0.69 \mu \mathrm{g} / \mathrm{mL}\right)$.

Stabilization of the red blood cell membrane has been used as a method to study anti-inflammatory activity in vitro because the erythrocyte membrane is analogous to the lysosomal membrane (Marliyah and Ananthi, 2015). 
According to the results obtained, the extract showed a significant stabilization of the red blood cell membrane compared to diclofenac sodium.

This stabilization implies that the phenolic extract of OMW can well stabilize the lysosomal membrane. Stabilization of the lysosome is important to limit the inflammatory response by preventing the release of lysosomal constituents from activated neutrophils, such as bacterial enzymes and protease.

Nonsteroidal drugs such as diclofenac sodium work either by inhibiting lysosomal enzymes or by stabilizing lysosomal membranes (SreeKumari et al., 2015).

According to Ghedira (2005), the strong anti-inflammatory activity is probably due to flavonoids, which corresponds to the production of superoxide anions $\left(\mathrm{O}_{2}{ }^{-}{ }^{-}\right)$by the membrane $\mathrm{NADPH}$-oxidase of activated leukocytes and by dismutation to that of the very reactive hydroxyl radical (OH.).

The strong anti-inflammatory of our extract may be due to the kampherol, 4.5-di-o-caffeoyquinic acid, and protocatechuic acid, which are abundant in the extract.

\subsection{Anticoagulant activity}

The anticoagulant effect of phenolic extract of OMW was measured using two in vitro assay methods: activated partial thromboplastin time (APTT) and prothrombin time (PT) (Kamal et al., 2007).

\subsubsection{Endogenous coagulation pathway (APTT)}

APTT assay was used to assess the inhibition of intrinsic factors of blood coagulation pathways such as F XII, XI, V, III IX, and prekallikrein (Rizzo et al., 2008). APTT assay use brain lipids and activators instead of platelets to detect VIII, IX, XI and excitatory releasing enzymes in the endogenous coagulation pathway to reflect the effects of endogenous factors on coagulation time.

The results of the anticoagulant activity obtained (Table 6) reveal that the extracts have dose-dependent anticoagulant activity. The clotting time (APTT) in the presence of polyphenolic extracts of OMW and their compounds and heparin had been determined.

The results show that the polyphenolic extract is capable of significantly increasing the APTT $(p \leq 0.01)$. The coagulation time of the phenolic extract of OMW obtained are (44.77 $\pm 0.25 \mathrm{~s})$ was higher than that of the negative control $(28.17 \pm 0.06 \mathrm{~s})$ and positive control $(33.1 \pm 0.1 \mathrm{~s})$. Our results were in the range of those obtained from (Kadi et al., 2020).

Therefore, the extract tested has a good anticoagulant activity with respect to the endogenous pathway.

\subsubsection{Exogenous coagulation pathway (PT)}

PT assay is assessed to examine the inhibition of the extrinsic coagulation pathway, especially factors $V$, VII, and X (Rizzo et al., 2008). PT assays are conducted by adding thromboplastin to plasma to reflect the effect of exogenous factors on coagulation time. 
In order to research an elongation at the level of the coagulation time, which is defined by an anticoagulant activity of the polyphenolic extracts of OMW with respect to the cascade of this pathway. A normal PT is between 12 and 14 seconds depending on the reagents used (Caquet, 2004).

The results obtained revealed that the incubation time of polyphenolic extracts with plasma significantly influences $(p \leq 0.05)$ their anticoagulant power.

Table 6

Anticoagulant activity of phenolic extract of OMW

\begin{tabular}{|lll|}
\hline & APTT (second) & PT (second) \\
\hline Negative control & $28.17 \pm 0.06$ & $13.4 \pm 0.1$ \\
\hline Extract & $44.77 \pm 0.25$ & $15.84 \pm 0.12$ \\
\hline Positive control & $33.1 \pm 0.1$ & $14.1 \pm 0.13$ \\
\hline
\end{tabular}

From the results obtained (prothrombin time) (Table 6), it appears that the extract is capable of significantly increasing PT. The coagulation times of the phenolic extract of OMW obtained are(15.84 \pm $0.12 \mathrm{~s})$ was higher than that of the negative control (13.4 $\pm 0.1 \mathrm{~s})$ and positive control (14.1 $\pm 0.13 \mathrm{~s})$. Our results were in the range of those obtained from (Kadi et al., 2020).

Therefore, the extract tested has a good anticoagulant activity with respect to the exogenous pathway.

Tomaru et al. (2005) demonstrated that the anticoagulant activity of heparin results from the inactivation of the coagulation enzymes of the endogenous path via forms a complex with anti-thrombin III.Since thromboplastin time is a coagulation test that explores all of the coagulation factors in the exogenous pathway,it is very likely that the anticoagulant activity of the OMW extract is due to the inhibition of one of these factors, which are activated in cascade.

In total and from the results, it can be deduced that the phenolic extract of OMW exerts an anticoagulant effect on the two coagulation pathways in a dependent manner.

Because thrombotic diseases have developed into the main causes of death, so effective anticoagulant drugs are urgently needed. Based on the above data analysis, it can be concluded that the phenolic extractof OMW has a certain anticoagulant effect in vitro and could be developed as an anticoagulant drug and applied to the treatment of coagulation-related diseases.

According to Ghedira (2005), flavonoids act on the blood vessels in the form of vitamin P activity, which is involved in maintaining the normal vascular permeability.

The strong anticoagulant activity of our extractmay be due to its richness in kampherol, caffeic acid, and its derivatives. 


\section{Conclusion}

The present study has made it possible to highlight the presence of bioactive molecules in olive mill wastewater. They are polyphenols, flavonoids and tannins, endowed with biological properties. OMW seems to present a real and potential interest by their antioxidant, anti-inflammatory and anticoagulant activities. These pharmacological properties of the polyphenols present in OMW allow the possibility of their therapeutic asantioxidant, anti-inflammatory and anticoagulant drugs. The extraction and reuse of polyphenols such as kampherol, 4.5-di-o-caffeoyquinic acid, protocatechuic acid, and quinic acid from OMW. This last is a dangerous source of environmental pollution, give us benefits from its biological properties, and in return, this will reduce its polluting impact, which has become a difficult problem for olive oil-producing countries.

\section{Declarations}

Authors' Contributions: All authors contributed extensively to the work presented in this paper, collect data, designed and performed research, wrote, revised and approved the final manuscript.

Conflict of interest: The authors declare that they have no known competing financial interests or personal relationships that could have appeared to influence the work reported in this paper.

Funding: This research did not receive any specific grant from funding agencies in the public, commercial, or not-for-profit sectors.

Ethical approval: This article does not contain any studies with human participants or animals performed by any of the authors.

\section{References}

Alaoui, N.S., El Laghdach, A., Stitou, M., Bakkali, A., 2016. Treatment and valorization of olive mill wastewaters. Mediterr J Chem 5(3):458-464

APHA, 2005. Standard Methods for the Examination of Water and Wastewater, 21st Ed., American Public Health Association, Washington, DC.

Ayoola, G.A., Coker, H.A.B., Adesegun, S.A., Adepoju-Bello, A.A., Obaweya, K., Ezennia, E.C., Atangbayila, T.O., 2008. Phytochemical Screening and Antioxidant Activities of Some Selected Medicinal Plants Used for Malaria Therapy in Southwestern Nigeria. Tropical Journal of Pharmaceutical Research, 7 (3), 10191024

Babić, S., Malev, O., Pflieger, M., Lebedev, A.T., Mazur, D.M., Kužić, A., Trebše, P., 2019. Toxicity evaluation of olive oil mill wastewater and its polar fraction using multiple whole-organism bioassays. Sci. Total Environ. 686, 903-914. 
Ben Saad, A., Jerbi, A., Khlif, I., Ayedi, M., Allouche, N., 2020. Stabilization of Refned Olive Oil with Phenolic Monomers Fraction and PurifedHydroxytyrosol from Olive Mill Wastewater. Chemistry Africa, 1-9. https://doi.org/10.1007/s42250-020-00179-8.

Calderón-Montaño, J.M., Burgos-Morón, E., Pérez-Guerrero, C., López-Lázaro, M., 2011. A Review on the Dietary Flavonoid Kaempferol. Mini-Reviews in Medicinal Chemistry, 11, 298-344. Bentham Science Publishers Ltd.

Caquet, R., 2004. 250 examens de laboratoire : prescription et interprétation (9éme éd), Masson (Paris), 388-389.

Cedolaa, A., Cardinalib, A., D'Antuonob, I., Contea, A., Del Nobile, M.A., 2020. Cereal foods fortified with byproducts from the olive oil industry. Food Bioscience 33 (2020) 100490

Chatterjee, P., Chandra, S., Dey, P., Bhattacharya, S., 2012. Evaluation of anti-inflammatory effects of green tea and black tea: A comparative in vitro study. Journal of Advanced Pharmaceutical Technology \& Research Apr-Jun. Vol. 3, p. 136-138.

De Leonardis, A., Macciola, V., Nag, A., 2009. Antioxidant activity of various phenol extracts of olive-oil mill wastewaters. Acta Aliment. $38,77-87$.

Dermeche, S., Nadour, M., Larroche, C., Moulti-Mati, F., Michaud, P., 2013. Olive mill wastes: biochemical characterizations and valorization strategies. Process Biochem. 48 (10), 1532-1552.

Dewanto, V., Wu, X., Adom, K., Liu, R.H., 2002. Thermal processing enhances the nutritional value of tomatoes by increasing total antioxidant activity. Journal of Agricultural and Food Chemistry, 50, 30103014.

El Moudden, H., El Idrissi, Y., Belmaghraoui, W., Belhoussaine, O., El Guezzane, C., Bouayoun, T., Harhar, H., Tabyaoui, M., 2020. Olive mill wastewater polyphenol-based extract as a vegetable oil shelf life extending additive. Food Processing and Preservation. 44 (12): 1-40

El-Abbassi, A., Saadaoui, N., Kiai, H., Raiti, J., Hafidi, A., 2017. Potential applications of olive mill wastewater as biopesticide for crops protection. Science of the Total Environment, 576, 10-21.

Ghedira, K., 2005. Les flavonoïdes : structure, propriétés biologiques, rôle prophylactique et emplois en thérapeutique. Phytothérapie, Numéro 4: 162-169

Goula, A.M. and Gerasopoulos, D., 2017. Olives and Olive Oil as Functional Foods: Bioactivity, Chemistry and Processing, First Edition. Edited by ApostolosKiritsakis and FereidoonShahidi. John Wiley \& Sons Ltd.

Govindappa, M., Naga, Sravya, S., Poojashri, M.N., Sadananda, T.S., Chandrappa, C. P., Santoyo, G., Sharanappa, P., Anil Kumar, N.V., 2011. Antimicrobial, antioxidant and in vitro anti-inflammatory activity 
and phytochemical screening of water extract of Wedeliatrilobata (L.) Hitchc. Journal of Medicinal Plants Research. Vol. 5(24), p. 5718-5729.

Kadi, K., Mrah, R., Hamli, S., Lekmine, S., Dib, D., Addad, D., Boukeria, S., Gueboudji, Z., Hafsaoui, I., 2020. Evaluation ofthe anticoagulant activity of margins from olives extraction in the Khenchela region. J. Fundam. Appl. Sci. 12(2),634-649.

Kamal, A.H., Tefferi, A., Pruthi, R.K., 2007. How to interpret and pursue an abnormal prothrombin time, activated partial thromboplastin time, and bleeding time in adults. Mayo Clin Proc 82(7):864-873.

Kandikattu, K., BharathRathna Kumar, P., VenuPriya, B., Sunil Kumar K., Ranjith Singh, B., Rathore, 2013. Evaluation of anti-inflammatory activity of canthiumparviflorum by in vitro method. Indian Journal of Research in Pharmacy and Biotechnology, 1 (5):729-730.

Karthik, K., Bharath, R.P., VenuPriya, R., Sunil Kumar, K., Ranjith Singh, B., Rathore, 2013. Evaluation of anti-inflammatory activity of canthiumparviflorum by in-vitro method. Indian Journal of Research in Pharmacy and Biotechnology $2320-3471$.

Khana, Y.H., Hadib, S.M., Mohammada, R.M., Azmia, A. S., 2020. Prooxidant anticancer activity of plantderived polyphenolic compounds: An underappreciated phenomenon. Functional Foods in Cancer Prevention and Therapy, 221-236

Makkar, H.P.S., Blümmel, M., Borowy, N.K., Becker, K., 1993. Gravimetric determination of tannins and their correlations with chemical and protein precipitation methods. Journal of Food and Agriculture, 61(2), 161-165.

Marliyah, M., Ananthi, T., 2015. In vitro anti-inflammatory activity of seed extract of Zea Mays (L.). Journal of Global Biosciences. Vol. 4, n5, p. 2168-2173

Morón, M.C., Pozo-Morales, L., Benito Mora, C., Garvi, D., Lebrato, J., 2018. OMW spillage control tool based on tracking p-Coumaric acid degradation by HPLC, Environmental Technology

Murugan, R., Parimelazhagan, T., 2014. Comparative evaluation of different extraction methods for antioxidant and anti-inflammatory properties from OsbeckiaparvifoliaArn.--an in vitro approach. J King Saud UnivSci 26(4): 267-275

Ozgen, M., Reese, R.N., Tulio JR, A.Z., Scheerens, J.C., Miller, A.R., 2006. Modified 2,2-Azino-bisethylbenzothiazoline-6-sulfonic acid (ABTS) Method to measure antioxidant capacity of selected small fruits and comparison to ferric reducing antioxidant power (FRAP) and 2,2'-diphenyl-1-picrylhydrazyl (DPPH)methods. Journal of Agricultural and Food Chemistry, 54, 1151-1157.

Petäjä, J., 2011. Inflammation and coagulation. An overview. Thromb Res 127:34-37. 
Power, S.K., Smuder, A.J., Kvarisan, H., 2010. Experimentale guide line for stadies designed investgate the impact of antioxidantssupplementation on exercuce performance international journal of spot nutrition and exircicemetabolism , $20: 12-14$

Rizzo, F., Papasouliotis, K., Crawford, E., Dodkin, S., Cue, S., 2008. Measurement of prothrombin time (PT) and activated partial thromboplastin time (APTT) on canine citrated plasma samples following different storage conditions. Research in Veterinary Science, 85: 166-170.

Serhan, C.N., Chiang, N., Van Dyke, T.E., 2008. Resolving inflammation: dual anti-inflammatory and proresolution lipid mediators. Nat. Rev. Immunol., 8, 349-61.

SreeKumari, C., Yasmin, N., Raffiq Hussain, M., Babuselvam M., 2015. In vitro anti-inflammatory and antiarthritic property of rhizoporamucronata leaves. International Journal of Pharma Sciences and Research (IJPSR). Vol. 6, p. 482-485.

Stoclet, J-C., Schini-Kerth, V., 2011. Flavonoïdes alimentaires et santé humaine. Annales Pharmaceutiques Françaises, 78-90.

Strukova, S., 2006. Blood coagulation-dependent inflammation. Coagulation-dependent inflammation and inflammation-dependent thrombosis. Front Biosci 11(1):59-80

Tomaru, T., Kawano, H.A., Tsujiuchi, Y., Suzuki, J.I., Nakajima, T., Uchida, Y., 2005. Mechanism of antithrombotic effect of heparin and antithrombin in balloon-injured arteries. Life Sciences, 77: 26112625.

Tzathas, K., Chrysagi, E., Lyberatos, G., Vlyssides, A., Vlysidis, A., 2019. Pretreatment of Olive Mill Wastes for the Extraction of Residual Oil and High Added Value Compounds. Waste and Biomass Valorization.

Uttara, B., Singh, A.V., Zamboni, P., 2009. Oxidative stress and neurodegenerative diseases: a review of upstream and downstream antioxidant therapeutic options. CurrNeuropharmacol 7: 65-74

Wang, J., Zhanga, Q., Zhang, Z., Songa, H., Li, P., 2010. Potential antioxidant and anticoagulant capacity of low molecular weight fucoidan fractions extracted from Laminaria japonica. International Journal of Biological Macromolecules, 46: 6-12.

Who, 2017. Cardiovascular diseases (CVDs). https://www.who.int/ news-room/factsheets/detail/cardiovascular-diseases-(cvds).

Wu, M.Y., Wen, D.D., Gao, N., Xiao, C., Yang, L., Xu, L., Lian, W., Peng, W.L., Jiang, J.M., Zhao, J.H., 2015. Anticoagulant and antithrombotic evaluation of native fucosylated chondroitin sulfates and their derivatives as selective inhibitors of intrinsic factor Xase. Eur J Med Chem. 92:257-269.

Xin, N., Li, Y.J., Li, Y., Dai, R.J., Meng, W.W., Chen, Y., Schlappi, M., Deng, Y.L., 2011. Dragon's blood extract has antithrombotic properties, affecting platelet aggregation functions and anticoagulation activities. $J$ 
Xu, X.Q., Liu, W.J., Li, W.Z., Liu, S.W., 2016. Anticoagulant activity of crude extract of Holotrichiadiomphalia larvae. J Ethno pharmacol. 177:28-34.

\section{Figures}

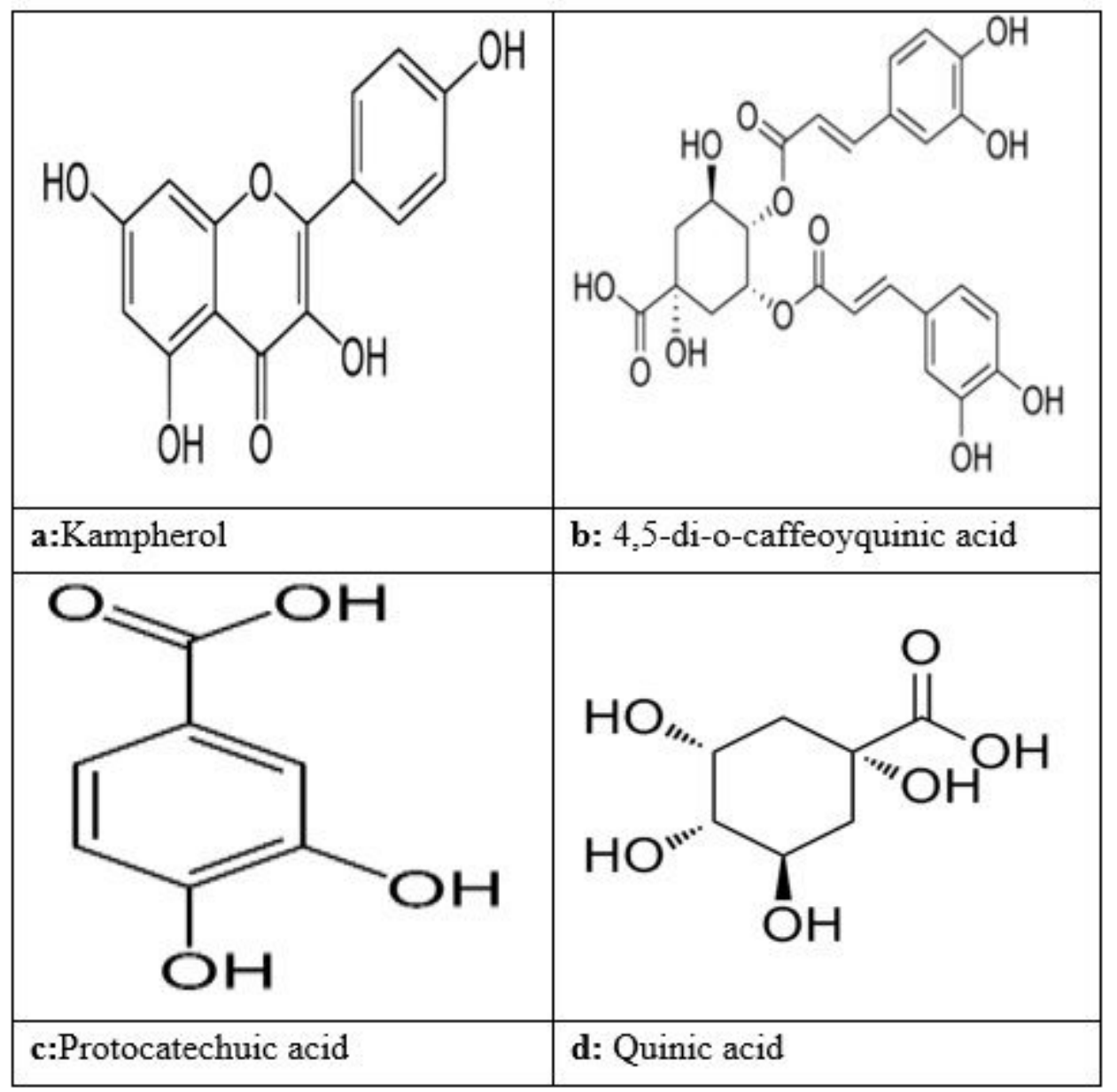

Figure 1

Chemical structure of major phenolic compounds (a: kampherol, b: 4,5-di-o-caffeoyquinic acid, c: protocatechuic acid, d: quinic acid) identified in OMW. 